\title{
Development of systems for monitoring stability of large excavations
}

\author{
Debashish Chakravarty and Srikant Annavarapu \\ Indian Institute of Technology \\ Kharagpur, India \\ dc@mining.iitkgp.ernet.in
}

\begin{abstract}
Current methods of geotechnical data collection require the engineers and technicians to cover large areas of surface and underground excavations to take measurements and assess field conditions and ground support response. The analysis of this information is most often done in the office and correlations between production activities, ground conditions and ground response are produced. The frequency of data collection is often weekly and this causes delays between observation of deformation and the implementation of measures to control ground movement. In the case of large excavations where speed is of the essence, systems need to be developed so that the time between observation and recommendation is reduced so that necessary steps can be taken to prevent any shortfalls in safety standards or production levels. Automation of data collection also helps reduce personnel interaction with large production equipment.
\end{abstract}

With the increase in the number of large excavations in the mining and civil construction sectors worldwide and the shortage of trained geotechnical engineers, the development of systems for monitoring ground stability in surface and underground excavations is challenging. This paper outlines the advances in technologies which can be used for safe and effective monitoring of the stability of surface and underground excavations.

Keywords—geotechnical monitoring; automation; drone survey.

\section{I.INTRODUCTION}

Infrastructure projects are being developed around the world resulting in the development of a large number of surface and underground excavations in different types of ground conditions. These excavations are being developed for various purposes including mining, transportation, liquid and gas storage, and hydro-power. The anticipated growth in the construction sector is around 3\% worldwide. The number of projects being developed and the need for monitoring the progress of the excavations to ensure adherence to schedule and budget has encouraged technology developers to undertake novel methods for assessing the progress of the projects. Construction budgets are also being tightened resulting in the requirement of improved designs with greater understanding of rock mass performance.

The growth in the worldwide demand for mined products has also led to the development of large scale underground and open pit mining operations around the world. While the industry is developing these large mines with greater degrees of mechanization to deal with the high rates of production, mine geotechnical engineers are struggling to help keep the excavations stable and safe for working. With a worldwide shortage of qualified and experienced geotechnical engineers, triggered in part by the worldwide economic slowdown, this task is becoming more and more difficult and has necessitated that the engineers be deployed to critical areas instead of requiring them to evaluate the stability in all the mining areas in an operating mine.

The monitoring of stability of large surface excavations, including mines, road cuts and slopes, requires the deployment of a large work force and/or instrument bases for the collection of appropriate data for analysis of the conditions during and after the construction. The installation and monitoring of suitable geotechnical instrumentation and the assessment of the risks during the construction of the project often yields localised results. In addition, the time taken for data gathering and analysis often slows down the rate at which the excavation can be advanced and also increases the risk to the stability of the excavation due to a delayed response to ground movement.

The construction of large underground excavations for hydro-power stations and large caverns for storage of petroleum products, including gas,can create considerable movement in the surrounding rock and the monitoring of such movement is critical to the safe development and maintenance of the excavations. Since the excavations are created in material which is variable in nature $[14,22]$, understanding the response of the ground to excavation loading often requires the use of numerical models to simulate the stresses and displacements surrounding the excavation. The calibration of these numerical models requires the use the monitoring data so that the response of the model can be matched to the field behavior of the geologic material in which the excavation is being created.

This paper presents some of the developments of instrumentation for geotechnical data and ideas for accelerating the development of automated geotechnical data collection and analysis in surface and underground excavations, the focus being primarily on instruments used for helping the geotechnical engineers in the monitoring of rock mass behavior.

\section{Current Practices In Monitoring Stability OF EXCAVATIONS}

Diligent evaluation, monitoring and examination of slopes for inferencing any suitable pattern is imperative for 
continuous production, safety of workers and that of the equipment. Geotechnical designs can be modified to increase the factors of safety and proper mine / structural designs can be implemented to minimize the associated geo-hazards. However, even slopes / structures with conservative designs may experience unexpected failure due to the presence of unknown geologic structures, abnormal weather and water patterns, and seismic shock. Unanticipated movement of any amount of rock mass may cause severe disruptions to mining operations, pose major safety concerns, or contribute to large financial losses for companies including huge time for resumption of the normal activities.

The successfulconstruction and usage of mining and civil construction excavations depends on the collection and timely assessment of geotechnical information to evaluate the safety and performance of the excavation. Current practices in geotechnical engineering require the regular inspections by trained geotechnical engineers and the installation of instruments for monitoring the changes in stresses and/or displacements around the excavations during construction and after completion of the excavations.

\section{A. Civil projects, including tunnels}

The development of large surface and underground excavations for civil infrastructure projects, including transportation and hydro-power, also require close monitoring for ensuring that the excavation can fulfil the designed purpose. Since most of these excavations are long lasting, the construction standards are significantly higher than those used in the mining industry. The installation of permanent excavation monitoring systems is also feasible in these excavations.

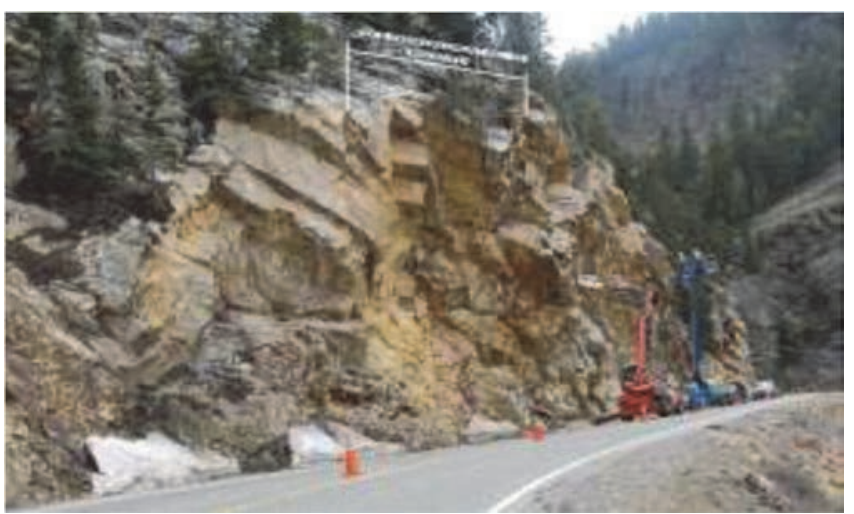

Fig. 1. Radar monitoring of a rock slope on the Red Mountain Pass in Colorado, USA

Large excavations for critical infrastructure and for road cuts often require the development of large slopes, which are designed to be stable for the life of the project. Though the designs incorporate high reliability, the monitoring of the slopes during and after construction and stabilization is required to ensure the safety of the working personnel and equipment. Traditional monitoring using inclinometers, wireline extensometers and surveyed prisms is undertaken to provide a cost effective solution. The introduction of continuous monitoring and real time assessment of stability can allow the users to improve the designed reliability of the slopes at a lower development cost. The use of slope monitoring radars, for example, allow for continuous slope monitoring and advance warning in case of slope movement (Fig.1), which is critical for safety especially while the construction is underway and the required support systems are not yet installed. The safety of the personnel deployed at the construction site is improved by using the early warning alarms built into such monitoring systems.

In a subway tunnel in Italy, two sets of three fixed lasers each were used to estimate vertical and horizontal convergence of the tunnel walls (Fig.2). The measurement accuracy of the laser convergence stations was in the millimeter range, which could provide adequate information on the onset of large deformation in the tunnel.

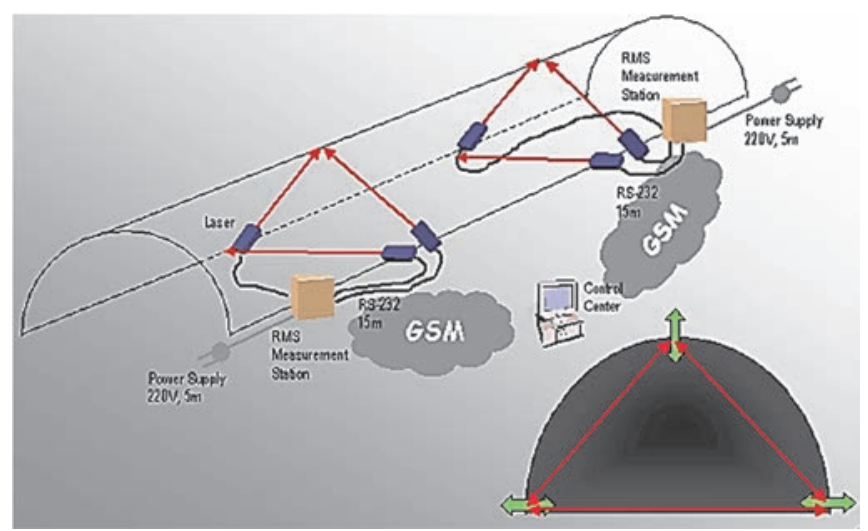

Fig.2. RMS laser monitoring system used in a subway tunnel in Napoli, Italy

While such measurements are applicable in the case of low displacement civil tunnels, main access ways and infrastructure excavations, the installation of lasers for convergence measurement in the tunnels in an operating mine may be less applicable in operating mine roadways where displacements can be substantial and a larger number of devices will be required to provide coverage to the vulnerable parts of the tunnels. In addition, these laser stations can be possibly knocked out of place by the operating mining equipment, which could result in damage to the instrument and possible erroneous readings due to change in the target angle. The system requires a large number of devices to effectively monitor and measure convergence in a mine tunnel.

\section{B. Surface mines}

In surface mining operations, even the smallest of failures can be problematic if the benches that support main haul roadsare compromised, or if facilities are threatened by displacement of the rock mass. Failure to adequately scale high-walls at quarries can also have devastating consequences has been seen in some of the earlier instances globally. Agencies such as MSHA in the USA provide information on the number of accidents caused by unexpected slope failures (Fig.3)

The type of instruments selected for slope monitoring depends on the particular problems to be monitored. A comprehensive monitoring system may include instruments capable of measuring rock mass displacement, ground water parameters, as well as blast vibration levels. Some of the commonly used monitoring systems are presented below. 


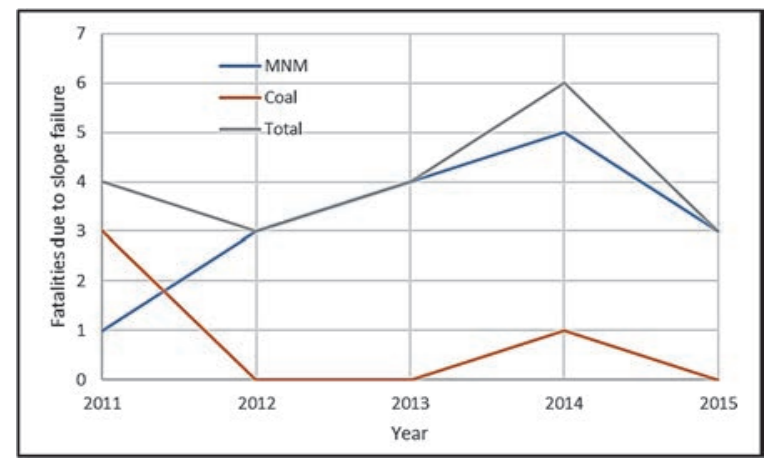

Fig. 3. Fatalities due to slope failure in USA 2011-2015

\section{1) Survey Networks}

Systems based on Electronic Distance Measurement (EDM) are cost-effectivemethods for monitoring of structures/slopes in surface mines. Target prisms are placed in and around the areas of anticipated instability and at one or more non-moving control points. Linear and angular measurements are taken on a regular basis from a survey station to establish a history of ground movement. These surveys can be done manually by a survey crew or can be automated (Fig.4).

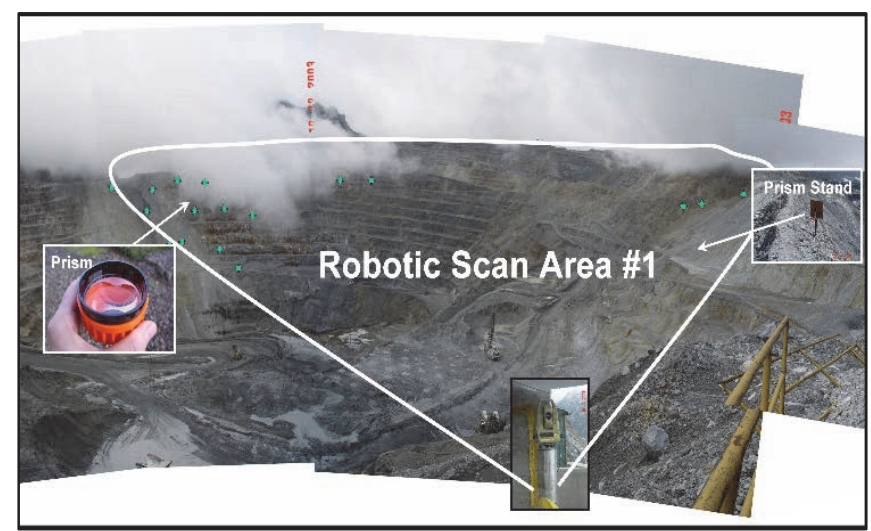

Fig. 4. Robotic scan of target prisms on a mine slope

\section{2) Piezometers}

Piezometers (Fig.5) are used to measure pore pressures and serve as valuable tools for assessing the effectiveness of mine dewatering programs. Excessive pore pressures, especially water infiltration at critical geologic boundaries, are responsible for many slope failures. Mine slopes should be thoroughly surveyed for new zones of movement after heavy rains or snowmelts.

\section{3) Wireline Extensometers}

Wireline extensometers are commonly used for monitoring movement across tension cracks. The most common setup is comprised of a wire anchored in the unstable portion of the ground, with the monitor and pulley station located on a stable portion of the ground behind the extreme end of the tension crack zone. The wire runs over the top of a pulley and is tensioned by a weight suspended from the other end. Electronically monitoring equipment can be programmed to set off warnings / alarms beyond certain threshold(Fig.6).

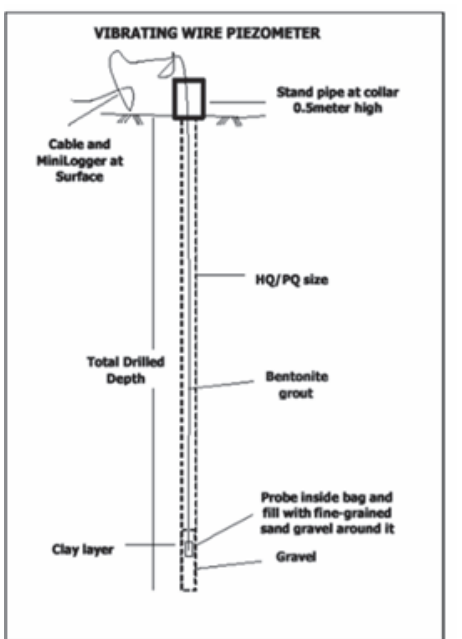

Fig. 5. Vibrating wire piezometer for monitoring pore pressure

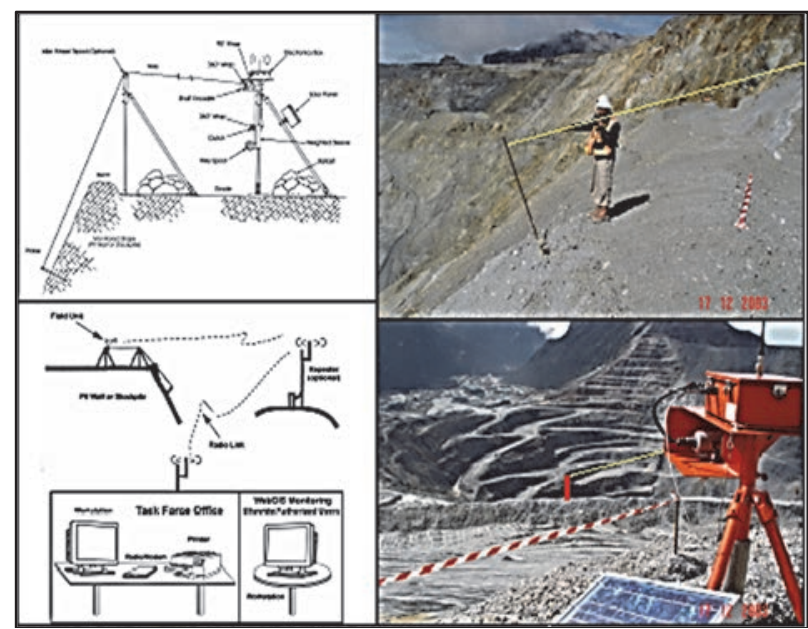

Fig. 6. Wireline extensometer system for slope monitoring

The length of the extensometer wire should be limited to approximately $60 \mathrm{~m}$ to have errors due to line sag at a minimum (Call and Savely, 1990). Sensitive extensometers need simultaneous temperature readings to adjust the errors. Provisions for keeping wildlife away from the instrumentation should be made at operations where this may be an issue to reduce false alarms.

\section{4) Inclinometers}

Normally an inclinometer consists of a casing placed on the ground through the weak areas. The end of the casing is assumed to be fixed so that the lateral profile of displacement can be calculated. The casing has grooves cut on the sides that serve as tracks for the sensing unit. The deflection of the casing, and hence the surrounding rock mass, are measured by determining the inclination of the sensing unit at various points along the length of the installations. Information collected from inclinometers can be used to (Kliche, 1999):

- Locate shear zones.

- Determine whether shearing is planar or rotational.

- Determine whether movement along a shear zone is constant, accelerating, or decelerating. 


\section{5) Slope Stability Radar system}

Analysis of the slope stability by scanning is a safetycritical and production issue for mines. A common technique to determine slope stability is to identify and monitor any small precursory movements, which occur prior to failure. Radar systems for monitoring slope stability (Fig.7) offer submillimeter precision and broad area coverage of wall movements through rain, dust and smoke. The real-time display of the movement of mine structures has allowed continuous management of the risk of slope instability at a mine operations level.

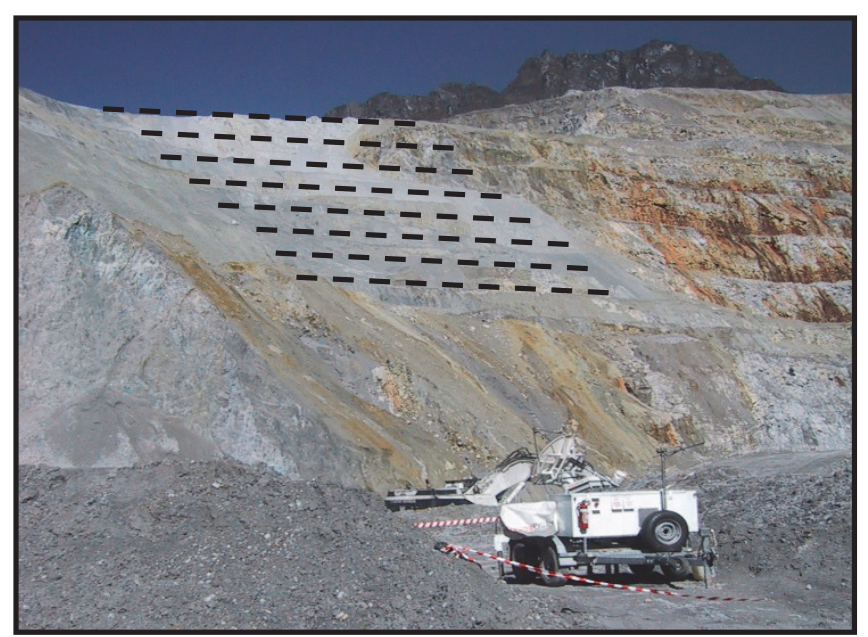

Fig. 7. Slope stability radar monitoring a mine slope

\section{6) Laser image scanning system}

3-D terrestrial laser scanning has become popular in the mining industry because of its high precision and speed, which surpasses that of the conventional point-measurement-based method. This technique captures the integrated and comprehensive panoramic views with high precision data. It also describes factually the frame and configuration of the ground object. The final estimates are closer to actual conditions. The rescaled range analysis method and a 3-D laser image scanning system are used to obtain structural information based on collected data. From this, the amount and characteristics of displacements may be analyzed for inferring the failure. Analysis of the data captured using a 3-D laser scanning system may be used to predict failures with better accuracy, but there are still some of the limitations in such types of analysis methods.

\section{Underground mines}

The philosophy of installation of supports in all underground locations within the particular space is mainly based on staged excavation, incremental installation of rock support, measurement and verification by monitoring with suitable feedback. In addition, robust design procedures need to be followed as per the 31st International Symposium on Automation and Robotics in Construction and Mining (ISARC 2014) to accommodate modification of rock supports based on actual characteristic of rock mass, thus leading to safe, cost effective, and practical rock support.
Rock mechanics engineers in the underground mining industry are still using simple mechanical and hydraulic instruments. The simplicity of the monitoring equipment is predicated by the harsh environments in the underground excavations in which sophisticated electronic equipment is subject to a larger degree of failure. However, electronic instruments are becoming more common due to their ability to be hooked up to a mine-wide monitoring network. Many of the instruments are more expensive than the mechanical and hydraulic instruments, but are now more robust and resilient, while being more sensitive to changes in the ground conditions. Two widely used different instrumentations types for the measurement of rock deformation around underground excavations are convergence monitoring by optical targets and rock mass deformation by extensometer. These measurements are most often limited to geotechnical or geological hotspots where the assessment of the information is necessary. This information is of limited use for the calibration of numerical models simulating the ground response around the excavations.

\section{1) Monitoring mine tunnels}

Convergence measurements using Reed-type tube extensometers and tape extensometers are most commonly used measure convergence in the underground tunnels in the mines. Measurements are made at convergence monitoring stations installed at regular intervals along the drifts (Fig.8). The cumulative closure and closure rates are evaluated using either graphs or contours and the cross-cut closure rates are related to stress levels and rock mass quality. These measurements provide an indication of movement and failure based on the interpretation of the closure rates.

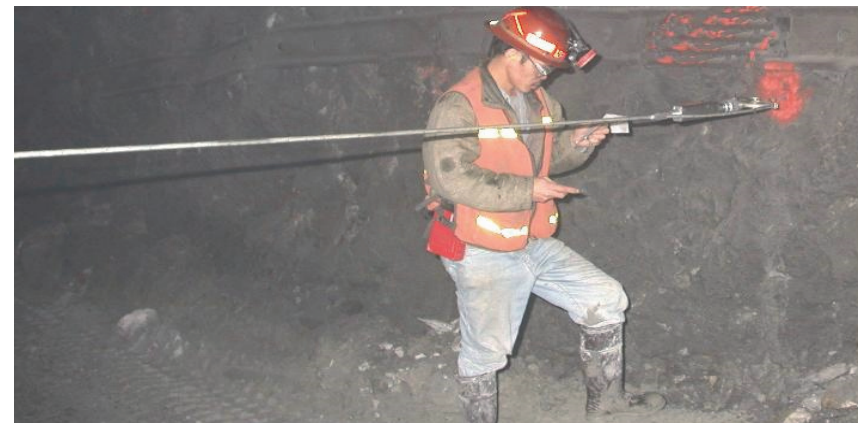

Fig.8. Convergence measurement in a tunnel (after Srikant, 2015)

In many cases the measurements are supplemented with single-point and multi-point borehole extensometers, which record deep seated movement around the mining excavations. The geotechnical engineer or technician also gets an opportunity to inspect the site while taking these measurements, which can form a valuable part of the database for rock mass behavior.

While the measurement method is the same, more and more sophisticated devices with electrical and pneumatic transducers have been developed over the years. Smart cables and optical fiber based displacement devices have been developed for collecting the information on a regular basis from the excavations and transmitting the data to the rock mechanics 


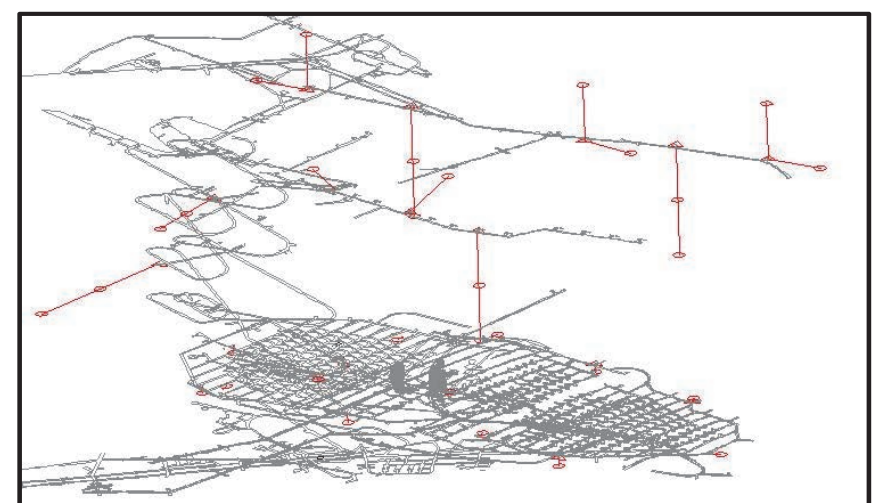

Fig. 9. Microseismic monitoring network at the DOZ Block Cave Mine (after Srikant, 2007)

engineer at a remote location. These developments enable the rock mechanics engineer to assess the data from the monitored areas and concentrate his efforts to those sections where critical ground control parameters have been exceeded. However, the instrument networks required to collect and transmit the data can be quite expensive and can be damaged in the tough mining environment, thereby reducing the efficacy of the network of instruments.

The use of inexpensive sensors and indirect assessments using micro-seismic methods is becoming more widespread especially in the larger mines (Fig.9).Qualitative and quantitative correlations between excavation parameters and the outputs from the instrumentation programs are being developed by the site rock mechanics engineers to help assess ground stability and to recommend remedial measures.

\section{Monitoring voids and orepasses}

Accurate images of the voids created by mining with the sublevel stoping methods are also of importance to understand the performance of the stopes in terms of ground stability and dilution. While the excavation size could only be roughly estimated using the tonnes drawn from the stope as a reference, the use of the LiDAR based cavity measurement systems (Fig.10) allows for the estimation of the amount and value of the ore left behind in the stope and the possible geotechnical hazards to be overcome to retrieve the ore. The instrument head is extended into the stoped void with the operator positioned in a safe area. The device then collects thousands of accurately located points that are used to determine size of a stope, orientation, volume and to create detailed engineering drawings. Repeated scans of the same area can be used to evaluate the stability of the void surfaces. Advances in wireless technology and the development of competitive devices has helped increase the ease with which these measurements can be taken and the accuracy of the measurements.

In addition, the use of laser scanners in the surveying of orepasses can help evaluate the stability of the ore-passes and the possible location and causes of hang-ups so that remediation plans can be appropriately developed (Fig.11). Several devices have been developed for generating video images and laser scans of the ore-passes and three-dimensional, geospatially accurate images of blockages within the ore-pass. Once the

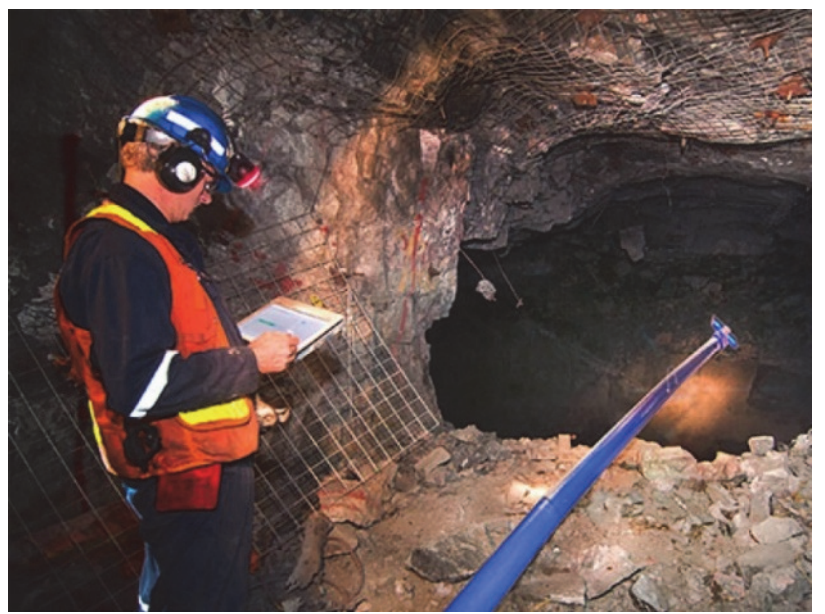

Fig. 10. Surveying an open stope using LiDAR (after Srikant, 2015)

location and nature of the hang-up or blockage is known, measures can be taken to dislodge the rock assemblage using blasting. In addition, the scan can help evaluate the cause of the blockage and measures to prevent future blockages in the ore-pass.

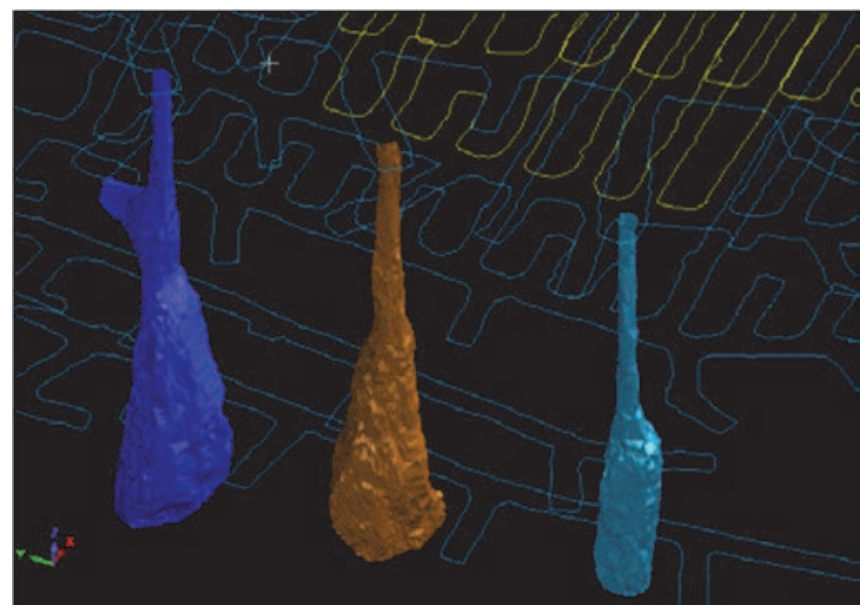

Fig. 11. Rendered solids from orepass surveys

\section{CHALLENGE IN GEOTECHNICAL MONITORING}

The scale of surface and underground excavations is constantly growing and the need for monitoring of the geotechnical conditions around these excavations is also getting more and more difficult. It is no longer possible to conduct visual inspections of all parts of the surface excavations with the smaller teams of trained geotechnical technicians and engineers. In the underground excavations, the geotechnical engineers can no longer reach up to the back or sidewalls to visually assess the conditions of the rock mass. In addition, the increased need to adhere to schedule and budget make it more challenging for the developers to incorporate the needs of the geotechnical engineers to inspect and assess the ground conditions before recommending a course of action. In some cases, the consulting geotechnical engineers are on standby as soon as a development face is blasted so that an inspection and assessment can be undertaken before the ground support team installs the recommended ground support. 
The development of large scale automated equipment for delivering the high production levels makes it difficult for the geotechnical engineers to collect the required geotechnical information in the old fashioned way. Development of innovative and efficient methods for data collection will allow the engineers more time for analysis of critical geotechnical parameters and will enable them to provide better and timely assessment of ground conditions so that necessary remedial actions can be initiated expeditiously with little disruption to production related activities.

New tools are constantly being developed for quick analysis of geotechnical data for civil engineering projects. However, mining excavations have shorter life, show larger degrees of movement and do not often provide the cleanest of environments for the deployment of sophisticated instrumentation. There is thus a growing need for the development of new and innovative methods of data collection from the large number of development and production faces in the existing and proposed surface and underground mines around the world. While the developments in data collection and analysis in the surface mines have been significant, instrumentation for geotechnical data collection in the underground mines has been limited.

\section{BACKGROUND FOR NEW TECHNOLOGIES}

Incorporating new technologies requires an understanding of the available systems for data gathering and assessment. Most of the solutions rely on the data gathered from LiDAR and digital images. The processing of these images to develop relevant monitoring outputs can be likened to the use of geophysical techniques for developing geological information. The advent of unmanned aerial vehicles (UAVs or drones), for carrying the required sensors to inaccessible positions to help better gather the desired information, has added a further boost to the improvement of geotechnical monitoring of surface and underground excavations.

The processes used for digital image processing have been constantly evolving with the increase in the resolution of lightweight cameras and the ability to develop three dimensional images from single cameras. Digital camera and image processing techniques provide tools to derive information from images where small differences between pairs of images can be readily detected and the changes can be quantified in pixel counts or area percentages, and images are time stamped for easy sequencing and visualization. These capabilities can be used to enhance slope monitoring.

Many researchers have used a camera-based images and carefully positioned reflectors to measure the deformation over time in an underground as well as surface mine structures. Processed film has been used to measure deflections to a resolution of $0.5 \mathrm{~mm}$, but the use of reflectors adds substantial complexity to the installation process and limits analysis to sites with reflectors. Digital image-based change detection approach can be used in a time lapse mode to record such things as bench loading, fracture development, creep and mass movements, and identification of fallen rock sources etc. A real-time slope monitoring system using low-cost video cameras can be used to generate rock fall warnings where workers and machineries could be at risk. These identifications would help minimize production losses.

The recent developments in the field of applied digital image based photogrammetric techniques with proper sensor integration have also been found to be useful for monitoring activities of opencast and underground spaces. The conventional processes are time consuming, laborious and need at skilled personnel to be employed for the operation to be completed. Digital image based photogrammetry on the other side is quick, reliable and a cost-effective process wherein the whole process can be handled by a single person and the results obtained through it are more accurate and promising [30]. Data collection with advanced digital techniques requiring knowledge of devices, memory and data integration with computers [26] are increasingly being used in the field operations.

\section{A. Digital Image Analysis}

Digital image and signal processing based approaches have a wide range of applications to accumulate data in accessrestricted, forbidden, or hazardous areas. In normal civil construction, transportation, mining activities digital technologies can be utilized for stockpile checking, high wall assessment (inferred information is typically utilized by geologists and geotechnical engineers). Elevated photogrammetry likewise has the likelihood to be executed into GIS frameworks for representation, displaying and monitoring and inspection purposes. A 3D coordinate measuring procedure and surveying such as triangulation [23] that utilizes multiimage $[3,13,19]$ based calculations to come up with the structural aspects is tried out us the present day commercial applications that are dedicated for one or the other industrial usages.

All the monitoring tasks are mainly carried out with the help of almost real time (if not real time) field data collected over a particular space which are intended to be associated with the particular process that needs to be monitored.

\section{B. Optical Targets}

The monitoring of the deformation of excavation surfaces of cavern can be undertaken based on 3D measurements of optical targets (in $\mathrm{x}-\mathrm{y}$ and $\mathrm{z}$ direction) in order to assess the rock mass behavior during and after excavation. Optical targets may be fixed to reference points on the rock surface using rock bolts. In caverns, the monitoring section may be typically at intervals of $25.0 \mathrm{~m}$ with targets placed in the roof and walls of the caverns. However, additional sections of optical targets may be installed at known geological features. All these targetsare normally installed after proper installation of supports at these locations. Necessary precautions need to be taken to protect the targets by dismantling from the bolts during blasting activity and replaced after the disruptive activity.

\section{Photogrammetry}

Digital air-borne photogrammetry is the development of estimations from photo/image streams using a processing sequence as shown in Fig. 12. The yield of photogrammetry is 
ordinarily a guide, drawing, estimation, or a 3D model of some certifiable article or scene. A hefty portion of the maps we utilize today are made with photogrammetry and photos taken from air ship.

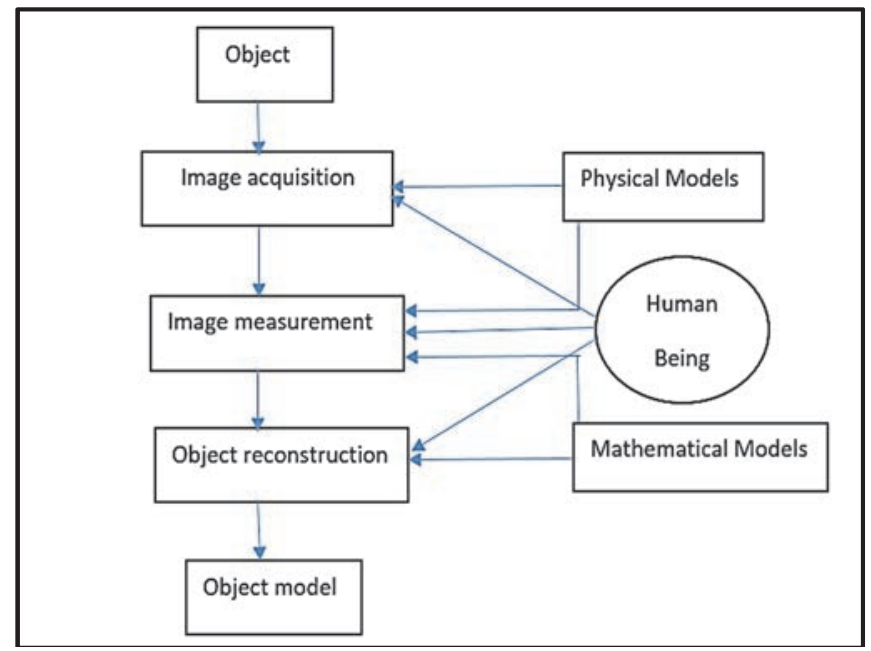

Fig.12: Digital image-based processing sequence

The acquisition of high quality digital images is fundamental for making image-based estimations. The three main considerations for good image-acquisition [18] are:

1. Field of View

2. Focus

3. Exposure

\section{1) Field of View}

The camera's field of perspective characterizes the amount it sees and is an function of the central length of the lens and the size (regularly called the arrangement) of the advanced sensor. For a given lens, a bigger organization sensor has a bigger field of perspective. Essentially, for a given size sensor, a shorter central length lens has a more extensive field of perspective.

\section{2) Focus}

Centering of the lens is important to ensure that the picture is sharp. The scope of adequate sharpness is known as the profundity of core interest. The profundity of the center of a lens comprises numerous components, including the central length of the lens, the arrangement measure, the separation from the camera to the article, the extent of the item, and the fnumber of the lens.

\section{3) Exposure}

For photogrammetry purposes, it is important to set the objectives as splendid and the foundation as faint. At the point when retro-intelligent focusing is utilized, the objective and foundation exposures are totally autonomous of each other. The objective introduction is totally controlled by the blaze power while the foundation presentation is dictated by the surrounding brightening. The measure of foundation presentation is controlled by the screen time.

\section{Metrology - the second part of photogrammetry}

Photography in its broadest sense is a procedure that changes the genuine 3-dimensional world into a level 2dimensional pictures. The camera is the gadget that makes this change or mapping from 3 measurements to 2 measurements. Unfortunately, we reverse-map the 2-dimensional photograph onto a 3-dimensional world completely since some data is lost (principally the profundity).

Photogrammetry inverts the photographic procedure depicted previously. It changes over or maps the level 2dimensional pictures once again into the genuine 3dimensional world. In any case, since data is lost in the photographic procedure, the 3-dimensional world cannot be completely recreated with only one photo. Two diverse photos are required to remake the 3-dimensional world. In the event that this procedure could be completely mapped, only two photos would be required to recreate the 3-dimensional world. Unfortunately, the photography and measuring procedure is not flawless so the reproduction of the 3-dimensional world is additionally defective. Additional photographs may be incorporated into this procedure so that the additional data in these photos can be used to improve the quality of the 3dimansional images. The 3-dimensional directions we deliver from the estimations of numerous photos are the deciding consequence of photogrammetry $[7,31]$.

The measuring framework for a planar surface measurement has been in view of short proximity photogrammetry to decide its exactness and accuracy. This framework is made from a computerized camera and a laser separation meter mounted on a backing that permits the laser separation meter to be moved freely of the camera. The proposed framework can decide the measurements of items. Additionally, this framework gives an estimation of the exactness of the computations for the separations between focuses. By knowing the instability of their estimations, clients can acknowledge or dismiss the estimation relying upon the application resilience [21].

Mechanical photogrammetry covers a full field of various viable difficulties as far as determined exactness, estimation speed, mechanization, process reconciliation, cost-execution proportion, sensor incorporation, and investigation. On-line and disconnected from the net frameworks are accessible, offering broadly useful frameworks from one viewpoint and particular turnkey frameworks for individual estimation undertakings on the other. Confirmation of precision and traceability to standard units as for national and worldwide models is unavoidable in modern practice. Framework arrangements can be isolated into the estimation of discrete focuses, distortions and movements, 6DOF parameters, 3D shapes and 3D surfaces [20].

Short proximity physical advanced photogrammetry and physical laser filtering was performed for brokenness portrayal on rock cuts. Physical remote detecting procedures are in effect progressively utilized as a supplement to conventional scanline and window mapping strategies. They give more extensive data on rock cuts, permit reviewing of blocked off outcrops, and expand client security. Chosen contextual investigations are utilized to evaluate the exactness of a few 3D model enrolment 
approaches and the most time, exertion and financially savvy strategies are highlighted. It is demonstrated that straightforward enlistment systems can give sufficient estimation of brokenness introduction for building purposes [8].

Improved attempts were undertaken to upgrade the pertinence of short proximity photogrammetry and shopper level computerized cameras to mishap reproduction. These incorporate the usage of strong on-line picture introduction; a strategy for programmed camera alignment, which utilizes shading coded targets [1].

Images (as shown in Fig.13) fora mining operation were adopted from the sample data provided in the PIX4D software. The sample data collected possessed a minimum of $60 \%$ overlap for the point cloud to be generated. The raw images produced from the metric cameras were transferred to a personal computer for the processing. These images were changed to .JPG format before inputting them into the software. The images were then loaded into the software and point cloud bundles were automatically generated in the project folder.

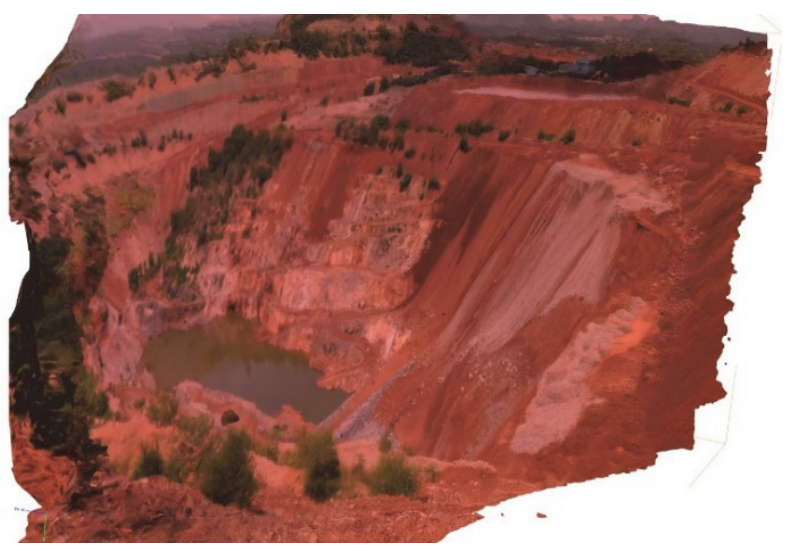

Fig.13: 3D Reconstructed Image of a Mining Operation

\section{Proposed TECHNOLOGIES}

The development of automation and communication systems has resulted in the growth of geotechnical monitoring systems which do not rely on the physical presence of a geotechnical engineer or technician. The data from recording stations is relayed to a central control station where the information is assessed in conjunction with other relevant data and recommendations are provided for speedy implementation of corrective measures. In many cases, the delay between data collection and provision of recommendations is significantly reduced so that the reliability of the excavation is improved. These technologies are useful for the monitoring of surface and underground excavations. While the processes are the same, the need for ruggedizing the equipment is possibly greater in mining applications.

\section{A. Monitoring surface excavations}

\section{1) Satellite based monitoring}

The use of satellite based techniques for the monitoring of surface mine activities has also been tried and reported in literature. Use of interferometric and other approaches have been applied for monitoring the structural deformations and using them for triggering an alarm system for easy evacuation of the workers as well as machinery deployed in and around the particular place of operation. The use of InSAR as an initial method allowing to determine the subsidence active area has grown worldwide (Fig. 14). The data from satellite images is also being used to complement other monitoring methods employing usually "classical" surveying techniques. The real production environment requires significant improvement of consistency of InSAR raw data before they can be used for real time deformation monitoring.

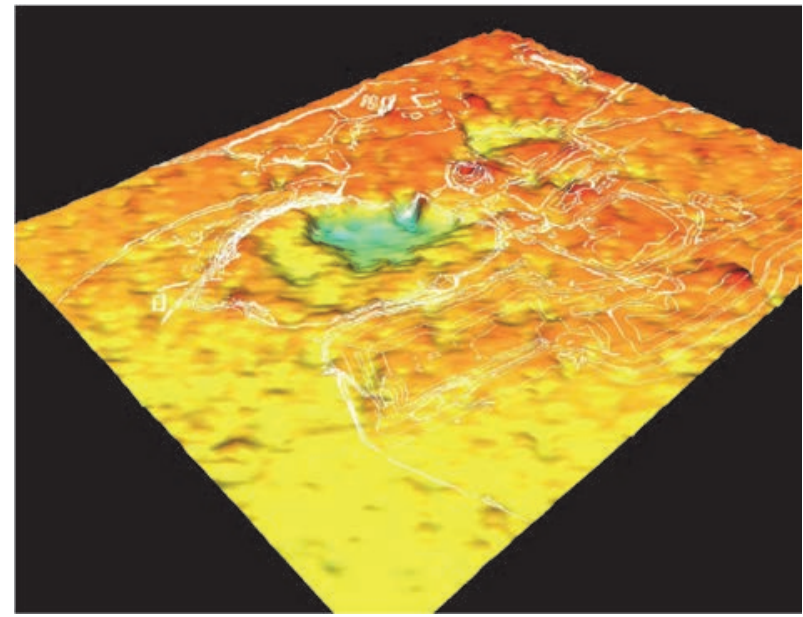

Fig.14: 3D representation of subsidence inferred using InSAR (after Jarosz and Wanke, 2003)

\section{2) Drone-based monitoring}

One of the most promising applications in the development of large surface and underground excavations is the use of UAVs or drones to assist in data gathering from remote locations (Fig.15).The drones can carry imaging sensors and devices for continuous recording or streaming so that the data is gathered safely by a geotechnical engineer. The analysis of the data can be done almost instantaneously and timely recommendations can be provided to the client.

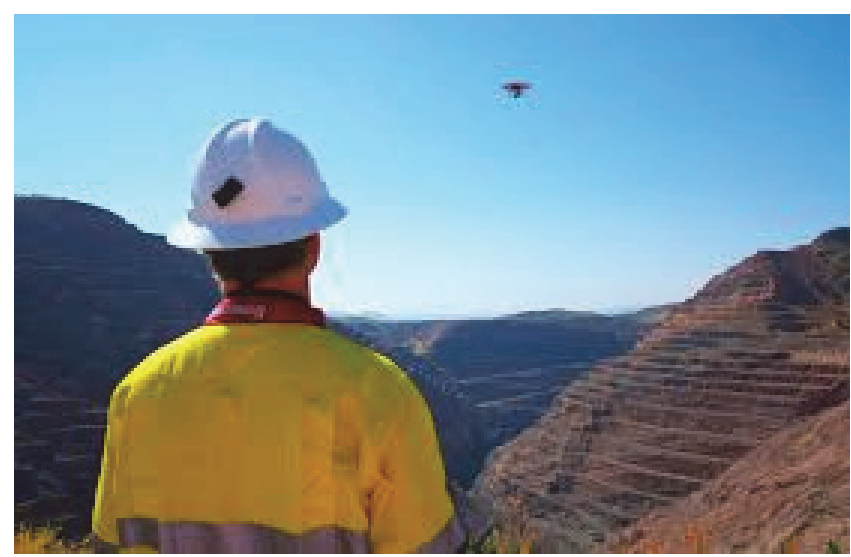

Fig.15: Drone flight in mine in Australia.

The time between working shifts can be analyzed for gathering and analysis of the geotechnical data. The use of 
photogrammetric methods in measurement has been revolutionized by UAVs. Due to the combination of microdrones and powerful, automated image analysis, new application areas are constantly being developed, such as surveying support of an open-cast mine (Fig.16). Several users are already relying on the processing of images collected by drones.

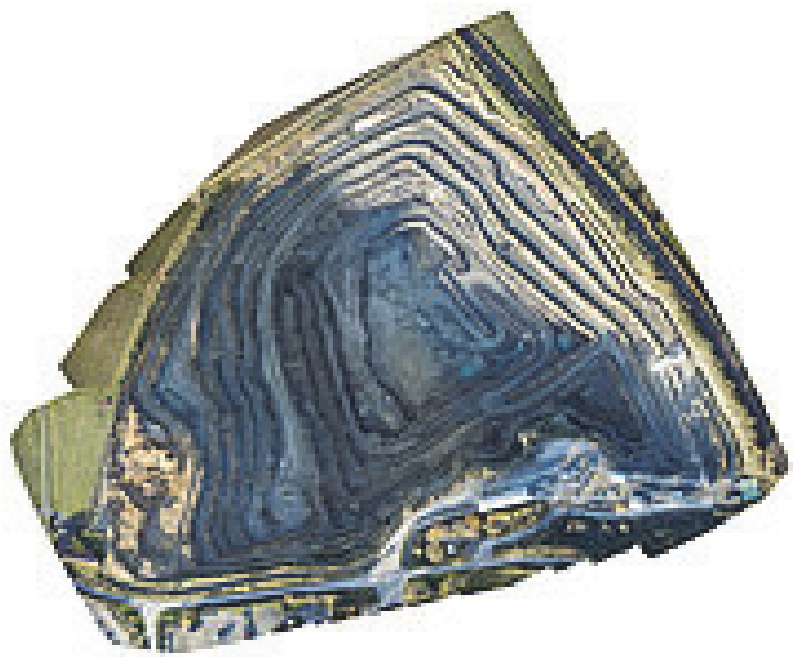

Fig.16: High-resolution, distortion-free recording of a quarry.

Geotechnical monitoring of slope movement at discrete intervals as recorded by drones can supplement data from other monitoring systems. This is one of the state-of-the-art technique used for monitoring the complete mining field with very high level-of-detail for the area under study. The structural information is used for the understanding and analysis of the stability and other aspects of the surface mine structure.

\section{3) Mobile robots}

This is the most recent approach which is still in laboratorybased prototyping stage where the robots (manual or semiautonomous) will be required to be sent to different part of the mine and carry out the data collection (Fig. 17), do the analysis and interpretation while providing the stability aspects of these structures on a real-time mode. Different instrumentation schemes may be adopted for this type of approach of monitoring the stability of structures. In future this approach will be made commercial.

\section{B. Measuring Tunnel Deformation}

Though several instruments have been developed for measuring tunnel deformation in the mines, the data is only collected at specific points in the tunnels selected mostly because of ease of installation of the instrument and the requirement envisaged at the time of installing the instruments. While we have the ability to access overall tunnel deformation using LiDAR scans of the tunnel taken at regular intervals, these techniques require the tunnel to be closed for mining operations during the scanning process. The deployment of a robot mounted with a suitable LiDAR scanner into the tunnel

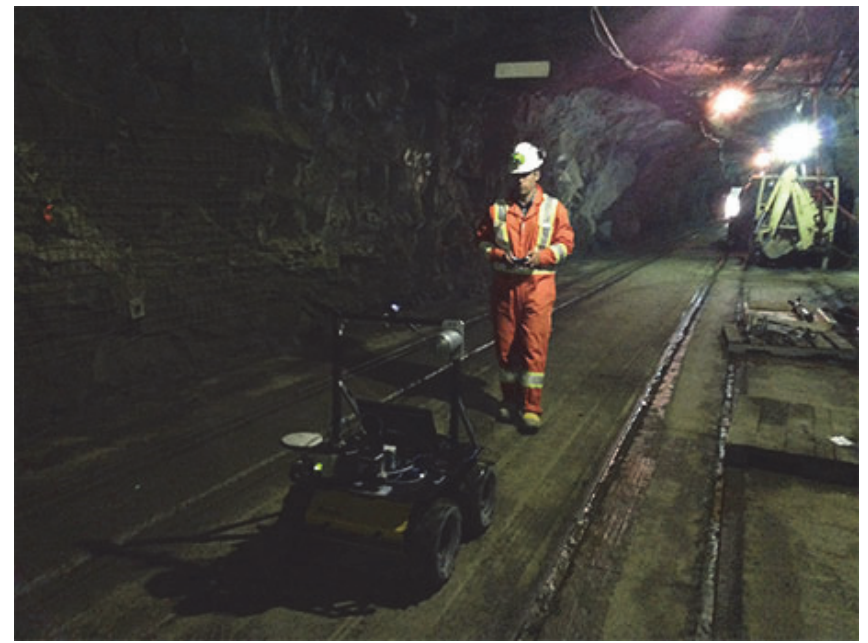

Fig.17: Robot being tested in NORCAT underground test center in Sudbury, Canada.

during a scheduled down time, such as immediately after blasting, will enable the rock mechanics engineer to generate and analyze ground stability information before persons are sent to the working areas (Bhushan et al., 2009). Knowledge of the extent of overbreak and the requirement of scaling can also help the mine engineers plan the equipment required at each work location and the time required to complete the operations, thereby increasing the utilization of equipment and preparing better forecasting for the production from the mine.

The proposed solution makes use of an inexpensive Unnamed Aerial Vehicle (UAV) such as Parrot Drone (Parrot, 2013) or DJI, 2014 Phantom (DJI, 2014). The low-cost drones would be released from safe known locations at a specified time after blasting or when ambient conditions are deemed safe by on-board sensors. Using inertial navigation and object avoidance technologies, the drone would negotiate the prescribed oath through a section of the mine creating a LiDAR scan of the path being followed. Waypoints installed in the mine would help constantly recalibrate the drone's location so that co-ordinates can be determined for the generated point clouds. Depending on the complexity of the mine operation, multiple drones can be deployed in different sections so that data can be collected from all locations in the mine. While drones have been navigated indoors, trials have also been conducted for self-navigating drones in an underground mine (Schmid et al., 2013).

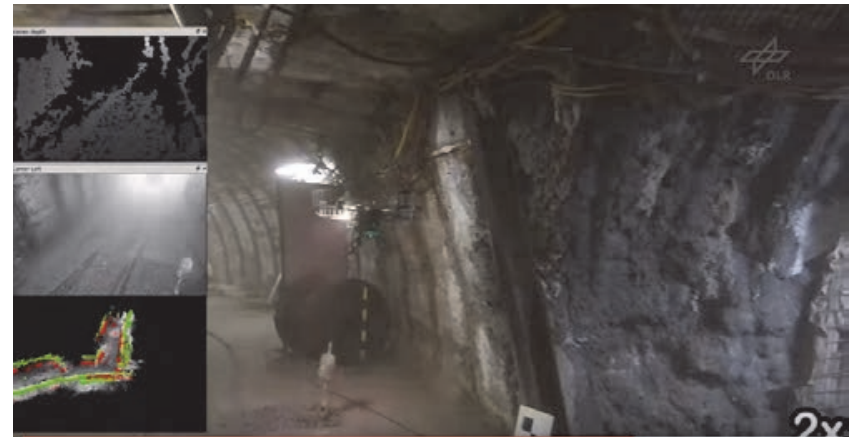

Fig.18: Autonomous quadrotor flight in a coal mine. 
Along with a low-light video camera and/or infrared camera, sensors can be mounted on the drone to collect LiDAR data and atmospheric data such as gas concentrations, heat, humidity, and dust levels. The drones can also help download data from remotely positioned continuous data gathering devices such as piezometers and stressmeters. The use of drones helps in the collection of data from the excavations when personnel are not in the area, thereby increasing the safety of data collection and reducing the amount of time in excavation cycle that is lost to data collection by personnel. The rock mechanics engineer is thus able to collect information from working areas, evaluate the ground stability issues and prioritize the site inspections so that they are most effective.

\section{Measuring Stope Dilution and Behavior}

Though much has been done in the field of data collection from out voids, the cost and time required to perform regular scans of these voids makes it difficult to conduct such operations in a large number of areas in a short period of time. The developments in drone technology for indoor flight with obstructions can be used for collecting this information from several stoping areas with minimal cost often using the down time for the deployment of the drones so that the information is available for taking necessary action to remedy possible hazards such as hang-ups and wedges in the stopes.

A tele-operated drone could be navigated into an open void and positioned at specific locations within the void (Fig. 19). Once in position, the LiDAR scanner could be activated to take a complete image of the void from that location. The images from multiple locations can be coalesced into a single image of the void, using the co-ordinates of the positions from where the images have been gathered. Repeated scans can reveal the sources of dilution, the results of blasting and the areas of movement in the stope walls. The images from the drones can also be used to estimate the fragment size distribution within the stope and, with the right sensors, the possible grade of the material within the stope.

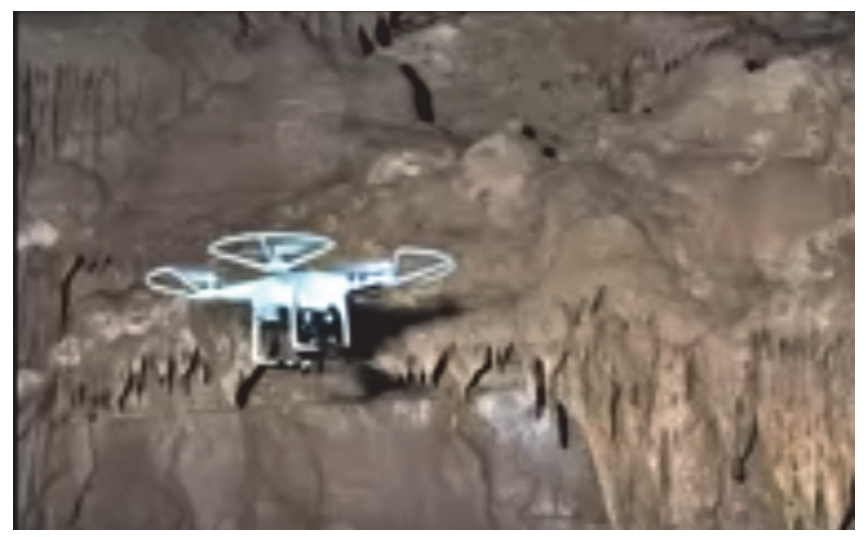

Fig.19: Phantom drone in Indiana Caverns cave.

Just as we can use drones for evaluating the behavior stope walls in large open stopes, they can also be used for the evaluation of conditions within an orepass. Apart from carrying a LiDAR scanner and a video camera to assist the operator in assessing the conditions in the orepass, the drone can also be equipped with explosive devices which can be targeted to the right area to dislodge a hang-up in the orepass with little risk to personnel and equipment. The drone is at risk during this operation, but is relatively inexpensive costing only a few thousand dollars. The development of sensors to work effectively in dusty and low-light environments and the algorithms to generate the necessary information from LiDAR data collected environments will help make these drones more effective.

\section{CONCLUSIONS}

India is a country where technological development is encouraged widely in almost every field of scientific and technological importance. The techniques for the measurement of ground stability parameters have changed in the recent years with the fast evolution in technology both in terms of hardware and software based approaches. Simple optical and mechanical instruments have quickly been supplanted with more complex setups like mechanized aggregate stations, and GPS. Computerized innovation has likewise entered in all parts of the process, from crude information gathering through guided accumulation and configuration to definite generation. Progress in mapping innovation has supplanted the customary stereoplotters with advanced imaging systems.

Air-borne / UAV based aerial imaging technique for georesource analysis is an efficient method of measuring geometrical features for various construction and mining engineering problems. This encompasses the camera calibration evaluation and the significance of different parameters followed by generation of point cloud in the cloud compare software. 3D Modelling of 2D images is done for this purpose. Overlapping of images gives variations in geometrical features for varying construction or mining sites. Method can be utilised for analysis of volume of excavation in opencast benches, progress of building construction at construction site, measurement of stock pile at material bunker site, estimation of fragmented rock at blasting site etc.

Though there can be many benefits in using drone technology in data collection in the mines, the hazardous and continuously changing physical environment in the mines can be an impediment to the implementation of the technology in a wide scale in the underground mines. The drones and the onboard sensors must be ruggedized to be able to operate in harsh conditions and operators will still be needed to evaluate the conditions in which the drone is being operated. The drones must be programmed to return to a "safe" location when an unsafe condition is detected and false alarms could be triggered making data collection difficult.

\section{REFERENCES}

[1] Akca, D., 2007. Matching of 3D surfaces and their intensities. ISPRS J. Photogr.Remote Sens. 62 (2), 112-121.

[2] Annavarapu, S. and Kumar, G.P., 2015. Development of Drones to Collect Geotechnical Data in Large Underground Mines. Proc. 37th APCOM, Fairbanks, AK, USA, 2015.

[3] Atkinson, K.B., 1996. Close Range Photogrammetry and Machine Vision, Whittles Publishing, Scotland.

[4] Bhushan, R., Heiberger, J., Helmers, A., Jensen, B., Kaitfors, E., Murtland, R., Oursland, J., Pluimer, M., Vickery, J., and Williamson, J., 2009. Design and Development of South Dakota School of Mines and 
Technology’s Aerial Robotic Reconnaissance System, First Symposium on Indoor Flight Issues, Mayagüez, Puerto Rico.

[5] Brown, E.T., 2004. Geomechanics: The critical engineering discipline for mass mining, Proc. MASSMIN, Santiago, Chile.

[6] Chen, C.S., and Lin, H.C. 1991, Estimating Pit-Excavation Volume Using Cubic Spline Volume Formula , Journal of Surveying Engineering, Vol. 117, No. 2, pp. 51-66.

[7] Cooper, M. A. R. and Robson, S., 1996. Theory of Close Range Photogrammetry, Close Range Photogrammetry and Machine Vision, 951.

[8] Cronk, S., 2007. Automated Methods in Digital Close-Range Photogrammetry. Thesis (Ph.D.), Department of Geomatics, Faculty of Engineering, University of Melbourne, Australia, 142pp. Record ID 41969442, National Library of Australia.

[9] Easa, S.M. 1988, Estimating Pit Excavation Volume Using Nonlinear Ground Profile, Journal of Surveying Engineering, Vol. 114, No. 2, pp. 71-83.

[10] Hyett, A.J., 2004. Innovative Digital Instrumentation for Geotechnical Monitoring Systems. Proc. 2nd International Symposium of Narrow Vein Deposits, Val d'Or, Quebec, CIM.

[11] Jarosz, A., and Langdon, J., 2007. Development of Inspection and Surveying Tool for Vertical Mining Openings and Shafts, FIG working week 2007, Hong Kong, SAR, China.

[12] Jarosz, A. and Wanke, D., 2003. Use of InSAR for Monitoring of Mining Deformations', Proc. of FRINGE 2003 Workshop, Frascati, Italy.

[13] Lillesand, Thomas M and Ralph W. K, 1979, Remote Sensing and Image Interpretation, JohnWiley and Sons, Inc, pp. 1-21.

[14] Patikova, A. 2004, Digital Photogrammetry In The Practice Of Open Pit Mining, ISPRS Xx. Symposium, Commission Iv, Wg Iv/7, Istanbul.

[15] Sabins F.F, 1997. Remote Sensing - Principles and Interpretation, 3rd edn., W.H.Freeman, New York, NY., 494 pp.

[16] Schmid, K., Tomic, T., and Suppa, M., 2013. Autonomous Quadrotor Flight in a Coal Mine.www.youtube.com/watch?v=hAOf2dA7CNM.

[17] Schulz, T., Ingensand, H. 2004, Influencing variables, precision and accuracy of terrestrial laser scanners, Ingeo, Bratislava.

[18] Singh A, 1989, Digital change detection techniques using remotelysensed data,International Journal of Remote Sensing, 10, pp. 989-1003.

[19] Srikant, A.,2007. Automation of geotechnical data collection in large underground mines. Proc. 33rd APCOM, Santiago, Chile.

[20] Sturm, P.F. and Maybank, S.J., 1999. A Method for Interactive 3D Reconstruction of Piecewise Planar Objects from Single Images, In: Proc. British Machine Vision Conference pp. 265-274.

[21] Van Den Heuvel,F.A., 1998. 3D reconstruction from a single image using geometric constraints ISPRS Journal of Photogrammetry and Remote Sensing, 53 (6) ,pp. 354-368.

[22] Yanalak, M 2005, Computing Pit Excavation Volume, Journal of Surveying Engineering, Vol. 131, No. 1.

[23] ADAM Technology- http://www.adamtech.com.au/3dm/analyst-miningaerial.html

[24] DJI, www.dji.com/product/phantom, 2014.

[25] Geodev Earth Technologies http://www.geodev.ch/pdf/ApplicationNote_Napoli_e.pdf, 2003

[26] http://www.geodetic.com/v-stars/what-is-photogrammetry.aspx

[27] Geosight, Inc., http://geosight.ca/, 2014.

[28] Optech Incorporated, http://www.optech.com/wp-content/uploads/specification_cms.pdf, 2014

[29] Parrot SA, http://ardrone2.parrot.com, 2013.

[30] http://www.tlvexp.ca/2013/09/field-view-dreams-matter-hosed/

[31] PhotoModelerhttp://www.photomodeler.com/applications/geology/default.html 